\title{
UPDATING GEOSPATIAL DATA BY CREATING A HIGH RESOLUTION DIGITAL SURFACE MODEL
}

\author{
Iuliana Adriana Cuibac Picu ${ }^{\text {a }}$ \\ ${ }^{a}$ National Center of Cartography, Cartography and Photogrammetry Department, 012101; Doctoral School, Technical University of \\ Civil Engineering of Bucharest, 020396, Romania, e-mail: iuliana.cuibac@cngcft.ro
}

Received: 14.10.2018 / Accepted: 12.11.2018/ Revised: 20.11.2018 / Available online: 15.12.2018

DOI: 10.2478/jaes-2018-0018

KEY WORDS: LiDAR, digital terrain models, Triangulated Irregular Networks, Aerial, LAS, point cloud.

\begin{abstract}
:
Smart Cities are no longer just an aspiration, they are a necessity. For a city to be smart, accurate data collection or improvement the existing ones is needed, also an infrastructure that allows the integration of heterogeneous geographic information and sensor networks at a common technological point. Over the past two decades, laser scanning technology, also known as LiDAR (Light Detection and Ranging), has become a very important measurement method, providing high accuracy data and information on land topography, vegetation, buildings, and so on. Proving to be a great way to create Digital Terrain Models. The digital terrain model is a statistical representation of the terrain surface, including in its dataset the elements on its surface, such as construction or vegetation. The data use in the following article is from the LAKI II project "Services for producing a digital model of land by aerial scanning, aerial photographs and production of new maps and orthophotomaps for approximately 50000 sqKm in 6 counties: Bihor, Arad, Hunedoara, Alba, Mures, Harghita including the High Risk Flood Zone (the border area with the Republic of Hungary in Arad and Bihor)", which are obtained through LiDAR technology with a point density of 8 points per square meter. The purpose of this article is to update geospatial data with a higher resolution digital surface model and to demonstrate the differences between a digital surface models obtain by aerial images and one obtain by LiDAR technology. The digital surface model will be included in the existing geographic information system of the city Marghita in Bihor County, and it will be used to help develop studies on land use, transport planning system and geological applications. It could also be used to detect changes over time to archaeological sites, to create countur lines maps, flight simulation programs, or other viewing and modelling applications.
\end{abstract}

\section{INTRODUCTION}

A "smart" city is a city that gathers information and uses modern technology to streamline traffic, improve public transport, living conditions, and reduce pollution and energy consumption.

Light Detection and Ranging (LiDAR) is a laser scanning technology that in the last two decades has become a much appreciated measurement method, providing high accuracy data and information about topography, vegetation, buildings and proving to be aa precise method of Digital Terrain Models (DTM) generation. LiDAR is using a laser scanning system with an integrated inertial measurement unit (IMU) and a Global Navigation Satellite System (GNSS) receiver that enables each measurement from the point cloud to be georeferenced. Combining more points to create a 3D representation of the object or of the area. Products obtained from LiDAR can be used to provide high accuracy - both absolute and relative - to allow data users to know the location of the collected data and the manner in which every point relates to the distance to the object it represents. This technology has replaced photogrammetry for more accurate Digital Surface Model (DSM) creation. LiDAR data, in the form of point clouds, can be used to map whole cities, allowing city decision makers to accurately identify structures or areas of interest in perfect details. Features and objects such as road networks, bridges, street details and vegetation can be easily classified. LiDAR products can also be used to highlight changes and anomalies such as surface degradation, slope changes and vegetation growth. A single pulse transmitted from an aircraft may have multiple returns. Part of the LiDAR pulse penetrates the vegetation cover and it is reflected on the ground surface (Clark et al. 2004). By identifying and isolating vegetation cover and artificial structures from the bare earth terrain, a DTM can be generated. However, in creating a DTM some constraints associated with the airborne scanner may include inadequate data to identify steep slopes and breaklines, and the areas of water bodies that are not covered by data (Uddin 2008). The main component of the LiDAR is the point cloud (ground and non-ground points). By using different interpolation methods such as Kriging, Inverse Distance Weight, Spline and Topo-to-Raster (Hutchinson's, 2011) a DTM is obtained after a classification process. LiDAR technology is also used in bathymetry and involves measuring the signal return time from object on the water to sensor, by using the green spectrum of the laser beam $(532 \mathrm{~nm})$. Two beams are projected into a rotating mirror, one of the beams penetrates the surface of the water and so detects the bottom of the water under favorable conditions. The most difficult part of LiDAR technology is the point cloud classification. In the last 
decade scientists have developed several techniques for classifying LiDAR data. The first classification method was proposed by Vosselman (2000). In this method, the difference in height between two points is defined as a morphological distance function. Filters have some disadvantages when there are tall buildings or small areas, in this case the building points will be classified as ground. Other methods of classification based on distance are: by Kilian et al. (1996), and Zhang et al. (2003). The second classification method is based on the progressive density of an irregular triangular network (TIN). In Axelsson (2000), ground points are classified by iterative construction of a triangular surface pattern. The third classification method is based on linear prediction and robust interpolation (Kraus and Pfeifer, 2001). The approach is made on a surface model defined for the entire set of points who is approaching iteratively to the surface of the ground. However, these two classification methods do not behave very well with the surface of small or complex objects, as reported by Sithole and Vosselman (2004).

Over the last 150 years, photogrammetry tools and techniques have progressed through four distinct phases of development and each time the access to technology and the quality of data derived from them have dramatically improved (Linder 2009). This development began with flat table photogrammetry (18501900). The photos were orientated base on points that are easy to identify, known as Ground Control Points (GCP). The next step, analog photogrammetry (1900-1960), is defined by the use of stereoscopy and aerial photographs. Specialists are ready to create the depth of illusion in images by simultaneously orienting and viewing two images, known as pairs of stereoscopic model, taken from the same area with GCP lesscompensated locations. Viewing and measuring stereo pairs has been tedious and has required costly training and good mechanical tools, but has helped create a correct topographic plan. The computers were inaugurated in the analytical photogrammetry era (1960-2000) and allow specialists to compute and record less costly distances and more easy-tohandle tools. However, this type of work is limited by the speed of the operator, and the size and quality of the images. The current step is digital photogrammetry (2000-present) and is characterized by the use of digital images and computer software that automates many tasks and requires little training and is more accessible than ever (Leberl \& Thurgood 2004). Recent advances in digital photogrammetry, allow software users to take measurements at a higher speed and resolution, at a lower cost than ever before. These qualities have shown the potential to improve many geospatial applications of photogrammetric measurements such as MDS (Lane et al 2000, Leberl \& Thurgood 2004, Jancso \& Melykuti 2011, Fonstad et al., 2013). The potential of digital photogrammetry has already been demonstrated for various applications and data sets, including aerial images, satellite images (Haala and Rothermel, 2012). Photogrammetric methods are converted from analog to digital (Honkavaara et al., 2008). Large-format photogrammetric digital cameras have been commercially marketed since 2000 (Camer, 2006). High-resolution and highquality digital cameras have improved image quality, which establishes a new potential for automatic image measurement and interpretation. Digital images, coupled with advanced direct georeferencing methods, make updated georeferenced images available to users within hours of collecting those (Honkavaara et al., 2008).
The object of this article is to obtain an accurate DSM, who can lead to a better geospatial data. DSM measures the height values above ground. This includes terrain features, buildings, vegetation and power lines etc. DSM therefore provides a topographic model of the earth's surface. DSM can be used to create 3D flight simulations, support location-based systems and augmented simulated environments.

\section{THE STUDY CASE}

\subsection{The LAKI II project - generalities}

The input data for this paper is based on LAKI II technical project.

In 2014, the National Agency for Cadastre and Land Registration, as project promoter, organised in Bucharest the launching conference of the project "Geographic Information for Environment, Climate Change and EU Integration (LAKI II)" funded within the EEA Grants 2009-2014 through the programme RO03 "Environmental Monitoring and Integrated Planning and Control". The main activities of the project comprises the production of a DTM through airborne laser scanning, new maps and orthophotos for approximately 50.000 sqkm of Romania's surface area located in counties such as Arad, Bihor, Mureş, Harghita, Hunedoara and Alba.

The products of this project are:

a. DSM and DTM with a resolution of $1 \mathrm{~m} \times 1 \mathrm{~m}$ (Figure 1):

- $\quad$ with high precision, for areas with high flood risk at the border of Romania with Hungary, in Arad and Bihor counties (surface of $10.000 \mathrm{sqKm}$, with a density of 8 points/sqm);

- with high precision for the county's capital cities corresponding to the 6 counties of the project (with a density of 16 points/sqm);

- adequate precision in the counties Hunedoara, Alba, Mureş, Harghita (surface of 40.000 sqKm, with a density of 2 points/sqm).

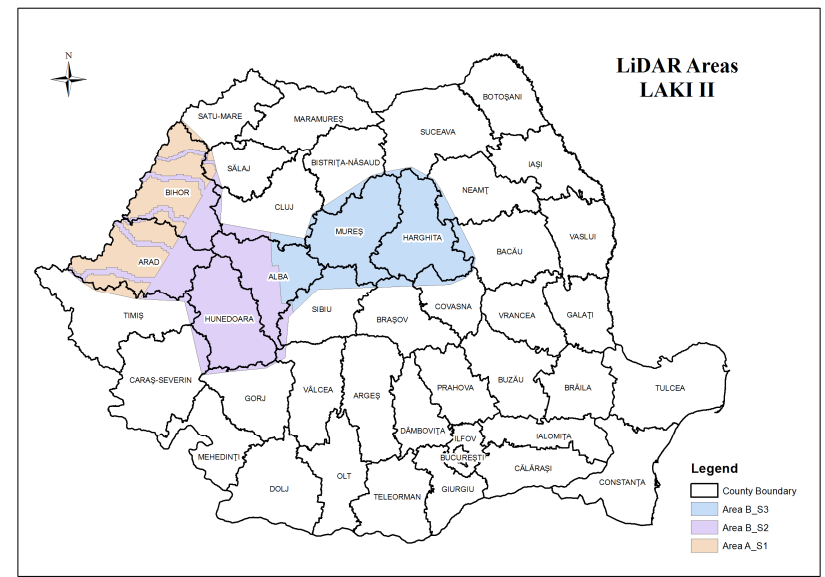

Figure 1. Project area for LAKI II- LiDAR data

b. Aerial photography and colour orthophotos for the counties Arad, Bihor, Hunedoara, Alba, Mureş, Harghita (surface 50.000 sqKm) with a resolution of $19 \mathrm{~cm}$ (Figure 2); 
c. 3D vector maps for the counties Arad, Bihor, Hunedoara, Alba, Mureş, Harghita (surface of 50.000 sqKm).

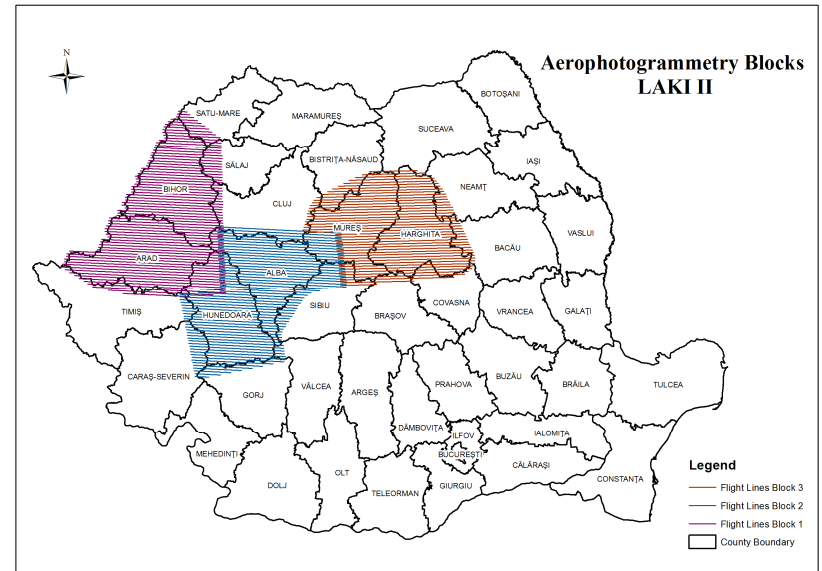

Figure 2. Project area for LAKI II- aerial images data

The LiDAR flight was conducted with the scanner RIEGL Q780(http://www.riegl.com/uploads/tx_pxpriegldownloads/Da taSheet_LMS-Q780_2015-03-24.pdf) mounted on a DA42 MPP plane type. The main features of the Q 780 scanner are:

- Full waveform scanning;

- Scanning angle $60^{\circ}$;

- Scanning mode: parallel lines;

- Diagnosis of laser radiation $<0.25 \mathrm{mrad}$

- Laser pulse repetition rate> $400 \mathrm{kHz}$;

- Effective measurement rate> $266 \mathrm{kHz}$;

- Precision: $20 \mathrm{~mm}$

The aerial images was acquired using digital cameras UltraCam Eagle Mark 2 and UltraCam Lp, mounted on a gyrostabilisator platform with both GPS and IMU systems. The images used in the following were acquired using the UltraCam Lp (http://www.gpsi-corp.com/UltraCamLp-Specs.pdf), who has the following technical characteristics:

- Focal distance: $70 \mathrm{~mm}$;

- Resolution: 11704 x 7920 pixels;

- Image format: JPEG or TIFF (8 or 16 bit);

- Physical pixel size: $6 \mu \mathrm{m}$;

- Spectrum images: R, G, B, NIR;

- FMC (Forward Motion Compensation)

- Integrated TDC controlled;

- Maximum FMC capacity: 50 pixels.

- Radiometric resolution:> 12 bits / color channel;

\subsection{Study area and input from LAKI II}

The chosen study area (Figure 3) is from Marghita city, in Bihor County and the surface of the area is one sqKm. The urban area chosen is one with higher buildings to highlight differences and to improve the DSM obtain from LiDAR technology with the one obtained from aerial images.

The aerial images were taken with Microsoft Vexcel's UltraCam Lp and the 3D point cloud was scanned with the RIEGL Q780 scanner with a density of 8 points / sqm.

The aerial images have a $60 \%$ longitudinal overlap and $30 \%$ side overlap and were taken with a ground sample distance
(GSD) of $20 \mathrm{~cm}$. In the chosen study were used 8 aerial images, orientation parameters both interior and exterior, and the ground control points (GCP) from that surrounding area.

The point cloud was delivered in LAS version 1.2 in the reference system - WGS 84 / UTM zone 34N. The point cloud consist of 14 million 3D points.

The software used in this paper are ERDAS Photogrammetry 2017 license soft and Cloud Compare open source soft.

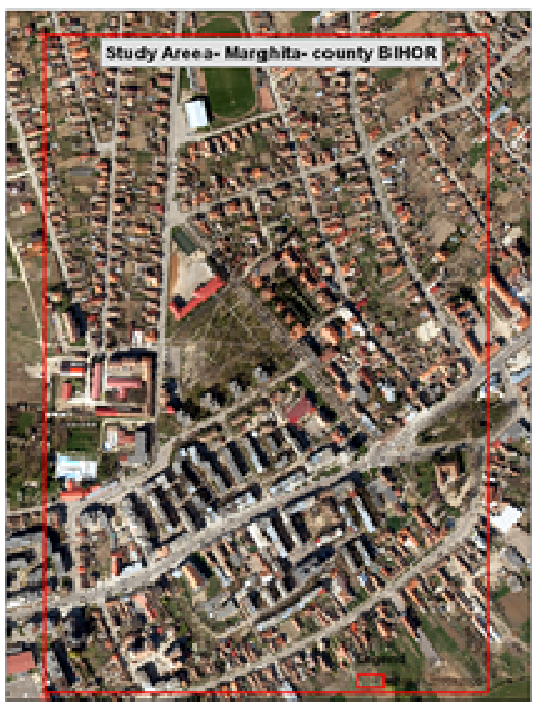

Figure 3. Study area

\subsection{DSM generated from LiDAR technology}

The first step was to reproject the point cloud into the National Reference System (Krasovski ellipsoid, Stereographic Projection 1970 and Black Sea 1975 Height System). The Stereo 70 projection is more accurate than the Gauss-Kruger projection and is a planar oblique projection. The central point of the projection is $45^{\circ} \mathrm{N}, 25^{\circ} \mathrm{E}$ and the origin axis system (northern fake and fake east) is $-500 \mathrm{~km}$ per $\mathrm{X}$ and $-500 \mathrm{~km}$ on $\mathrm{Y}$. The cutting plan is lowered to $3502 \mathrm{~m}$ and the tangent and the circle 102 zero deformations has a radius of $201,718 \mathrm{~km}$ (https://www.geotrafo.com/index.php?page $=$ coosystems\&lang= en). LAS is a "binary format file that maintains the specific information of the LiDAR data, while this is not too complex" (ASPRS, 2007). LiDAR data may contain, besides the $x, y, z$ coordinates, the next additional information: intensity, point classification (if it was performed), number of returns, processing time, scanning line.

The LiDAR intensity is given not only by the reflexivity, the moisture, the roughness and other surface properties, but also by the dynamic geometric relationship between the sensor and the geometry dynamics of the target-sensor, that includes the length of the laser wave (Donoghue et al., 2007, Langford et al., 2006). In this study case the point cloud from LiDAR was RGB encoded, from the orthophoto.

Using the Colour Encode function from ERDAS Photogrammetry 2017 software, each point has been assigned the RGB code from the image pixel. 
Nearest neighbour algorithm for the areas with large gaps, such as waters, using the grid's height. This method of interpolation is a distribution function that is defined in relation to some point of a point process already existing. The nearest neighbour function is defined as follows:

$$
D x(r)=1-P(N(b(x, r)=1 \mid x))
$$

$$
\text { where: } \begin{aligned}
& D=\text { the distribution function } \\
& \mathrm{P}=\text { point located in } \mathrm{b}(\mathrm{x}, \mathrm{r}) \\
& \mathrm{x}=\text { arbitrary point location }
\end{aligned}
$$

After the interpolation, the point cloud has been filtered based on heights for vegetation, the min slope, and the max and min area, the min height the result being a classified point cloud (Figure 4). For an improved output, after the automatic classification, a manual one was performed (Figure 5). The resulted point cloud has 13 million 3D points.

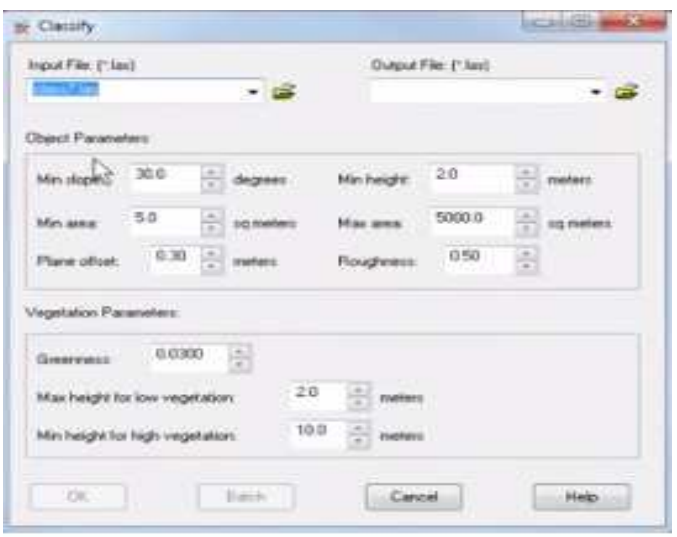

Figure 4. Parameters for point cloud classification

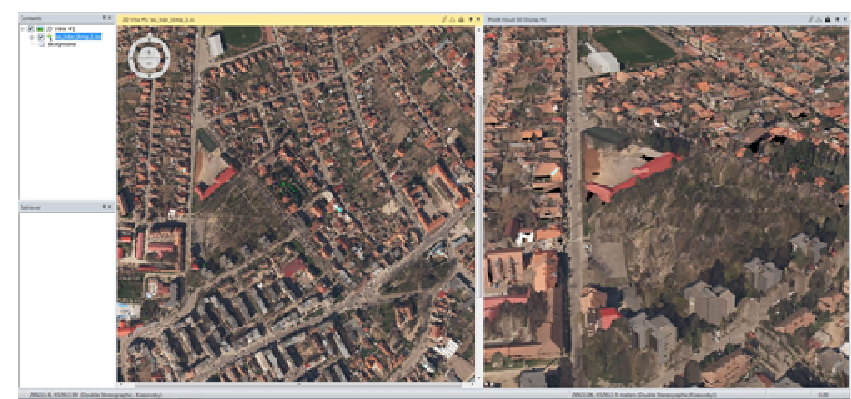

Figure 5. Classificated point cloud

For the DTM generation the following steps were performed: from the point cloud a TIN was generated. TIN format is: a model of the surface using irregularly-spaced points and lines. Many approaches have been developed to create TINs from elevation data and most methods are based on Delaunay triangulation (Cazals and Giesen, 2006; Dey, 2006). In a Delaunay triangulation the circumscribing circle of each triangle contains no other points, thus maximizing the minimum angle of each triangle. However, the final result of a TIN method may not strictly be a Delaunay triangulation and slight difference in the generated surface may result. TIN format can more accurately model the terrain surface than a raster, but it usually requires a more computationally expensive method to be adopted.
Based on the TIN format of the point clouds, a grid was generated, disregarding the density (raster type with a $10 \mathrm{~cm} \mathrm{x}$ $10 \mathrm{~cm}$ resolution). The height value obtained by triangulating in the grids' cells centre was used. The DSM has been derived from all the valid points on the earth (on the ground or above) and can be seen in Figure 6.

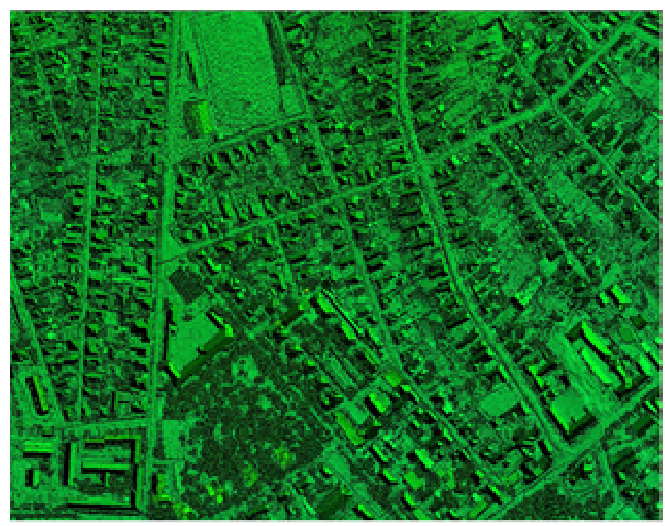

Figure 6. DSM from LiDAR data $(10 \mathrm{~cm} \times 10 \mathrm{~cm})$

\subsection{DSM from aerial images}

A Photogrammetric project base on the reference coordinate system, the datum, the units, and the used camera has been created (Figure 7). For the next step the 8 images from the study area were imported. Pyramid layers for the images in the block were computed. Pyramid layers are used to optimize image display and automatic tie point collection. Using this pyramids, image contents are preserved and computation times is reduced. The parameters for the interior and exterior orientation were defined. The pixel size is $5.7 \mu \mathrm{m}$. The coordinates of the projection centres of the images and the rotation angles were defined to generate the exterior orientation. The data from the LAKI II project has ground control points measured in the field. Aerial triangulation is the process of establishing a mathematical relationship between the images, the camera or sensor model and the ground. The information resulting from aerial triangulation is required as input for the orthorectification, DSM creation, and stereo-pair creation processes (Leica 2006). For this step was used the Orima application of the software and were generated tie points in the overlap areas. The Root Mean Square (RMS) of the aerialtriangulation was $0.07 \mathrm{~m}$.

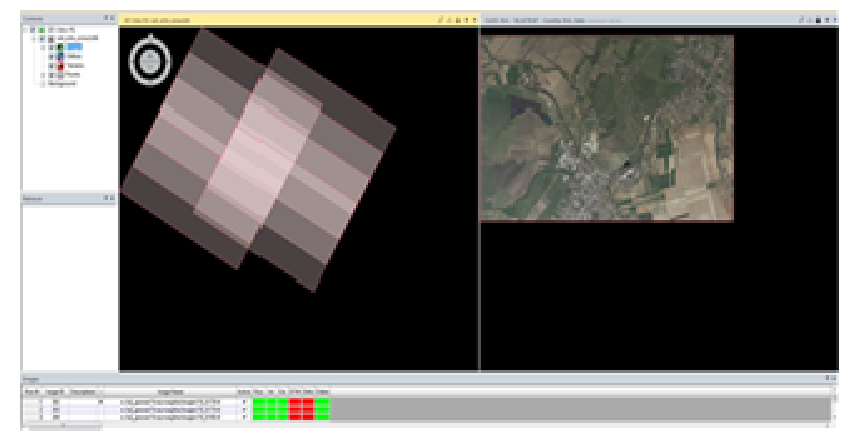

Figure 7. Photogrammetric project in ERDAS

Semi-Global Matching (SGM) is the latest technology developed to further enhance the advantages of the 
Zeiss/Intergraph DMC-II-140 aerial mapping system (Bethmann, 2014). SGM is a widespread algorithm for image matching to generate $2.5 \mathrm{D}$ point cloud. Originally developed for stereo-image matching, several extensions have been proposed to use more than two images within the matching process (multibaseline matching, multi-view stereo). Most of these extensions still perform the image matching in (rectified) stereo images and combine the pairwise results afterwards to create the final solution. SGM is employed in the optimization step, as it defines a global 2D energy function $E$ that depends on the disparity map dimension (E. Karkalou, C. Stentoumis, G. Karras, 2017):

$$
E(D)=\sum_{P}\left(\begin{array}{l}
\left.C\left(p_{2} D(p)\right)+\sum_{q=N_{p}}\left(P_{1} T \prod D(p)-D(q) \mid=1\right)\right) \\
\left.+\sum_{q=N_{p}}\left(P_{2} T \prod D(p)-D(q) \mid>1\right)\right)
\end{array}\right)
$$

where: $\quad C(p(D(p)=$ is a date term for each pixel $\mathrm{p}=$ pixel

$\mathrm{N}_{\mathrm{p}}=$ the neighbourhood

XPRO SGM was used to generate the point cloud in LAS format (8 million points) and the DSM raster with a resolution of $20 \mathrm{~cm} \times 20 \mathrm{~cm}$.

\subsection{Difference between the two generated DSM}

To highlight differences in point cloud metadata for both LAS files were use the histograms from these two types of data (point clouds-2.5D and 3D in the open source software -Cloud Compare shown in Figure 8 and 9).

Gauss: mean $=4.713351 /$ std dev $_{.}=1.718212[2983$ classes $]$

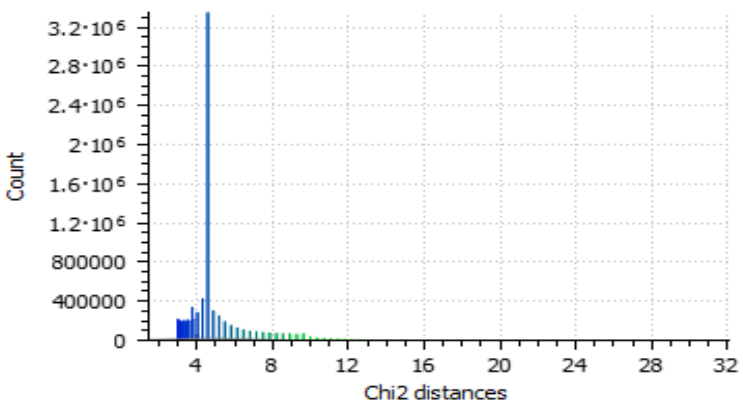

Figure 8. The Gauss Histogram of the point cloud by LiDAR

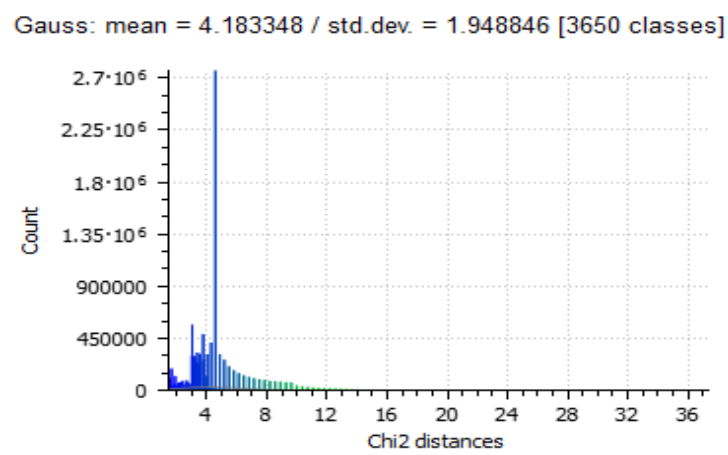

Figure 9. The Gauss Histogram of the point cloud by aerial images
The difference it is seen in the number of classes, the mean and the standard deviation between the two point clouds.

The comparison started by visualizing the differences in the software application and by measuring the point from the DSM obtain by LiDAR technology. From the measurements it can be seen that the DSM from LiDAR is located above the ground points from the stereo model, and that means that one of them is generated wrong (Figure 10).

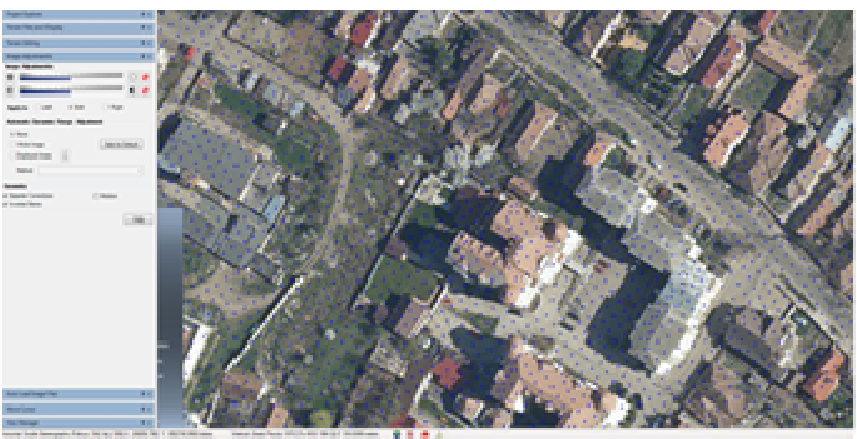

Figure 10. The stereo model obtain by aerial images and the DSM from LiDAR date

Also in the point cloud selection were performed some measurements in both LAS files (the point cloud from LiDAR and the point cloud from aerial images) shown in Figure 11 and the results written in Table 1:

Table 1. The results from the point's measurements in Stereo Models

\begin{tabular}{|c|c|c|c|c|c|c|c|c|}
\hline \multicolumn{7}{|c|}{ Diference betwen point cloud from LiDAR and point cloud from aerial nadiral images } \\
\hline \multirow{2}{*}{$\begin{array}{c}\text { Nr. } \\
\text { Crt }\end{array}$} & $\begin{array}{c}\text { Tip de } \\
\text { măsurătoare }\end{array}$ & \multicolumn{2}{c|}{ Coordonate DSM-aerial imagine } & \multicolumn{2}{|c|}{ Coordonate DSM-LiDAR } & $\begin{array}{c}\text { Diferen } \\
\text { ce }\end{array}$ \\
\cline { 5 - 10 } & $\mathbf{X}(\mathrm{m})$ & $\mathrm{Y}(\mathrm{m})$ & $\mathrm{Z}(\mathrm{m})$ & $\mathrm{X}(\mathrm{m})$ & $\mathrm{Y}(\mathrm{m})$ & $\mathrm{Z}(\mathrm{m})$ & $\mathrm{Z}(\mathrm{m})$ \\
\hline 1 & $\begin{array}{c}\text { Point on the } \\
\text { street }\end{array}$ & 298852.810 & 653236.330 & 135.090 & 298818.350 & 653217.350 & 140.940 & -5.850 \\
\hline 2 & $\begin{array}{c}\text { Point on the } \\
\text { ground }\end{array}$ & 298853.270 & 653244.100 & 134.980 & 298829.020 & 653218.660 & 140.790 & -5.810 \\
\hline 3 & $\begin{array}{c}\text { Point on the } \\
\text { roof }\end{array}$ & 298866.710 & 653291.420 & 145.330 & 298839.440 & 6523264.780 & 155.130 & -9.800 \\
\hline 4 & $\begin{array}{c}\text { Bulinding } \\
\text { Height }\end{array}$ & & & 8.790 & & & 10.890 & -2.100 \\
\hline 5 & $\begin{array}{c}\text { Bulinding } \\
\text { Height }\end{array}$ & & & 21.940 & & & 16.520 & 5.420 \\
\hline 6 & $\begin{array}{c}\text { Bulinding } \\
\text { Height }\end{array}$ & & & 9.010 & & & 8.500 & 0.510 \\
\hline
\end{tabular}

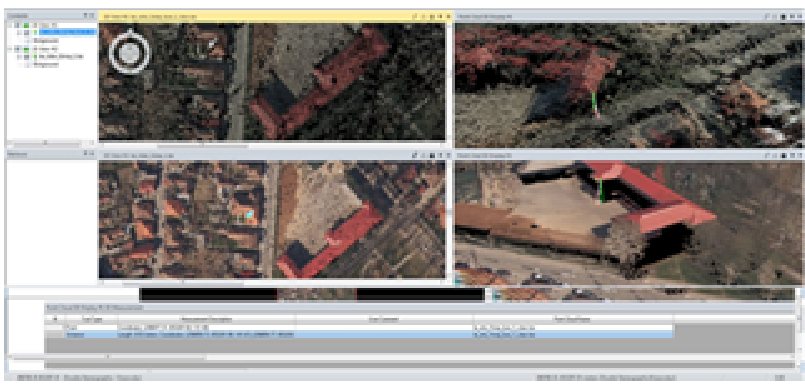

Figure 11. The measurement taken in the point cloud

The next step was the comparison between the two obtained DSMs using the open source software. After uploading the DSM cloud (e.g. .las format) or the 3D point cloud, you can perform visual assessments, generate cross-sections, compute 
cloud-to-cloud differences, generate best-fitting planes and measure point-to-plane distances/flatness error, etc.

The aligning of the two point clouds was made using tools from this software. The reference was the point cloud from the LiDAR technology. There were selected 15 points for the aligning, but the points with the maxim errors were eliminated. After the alignment process (Figure 12) the results are displayed, such as the final RMS $=1.31625$, the scale of 0.996 and the matrix transformation (Oniga E., 2017).

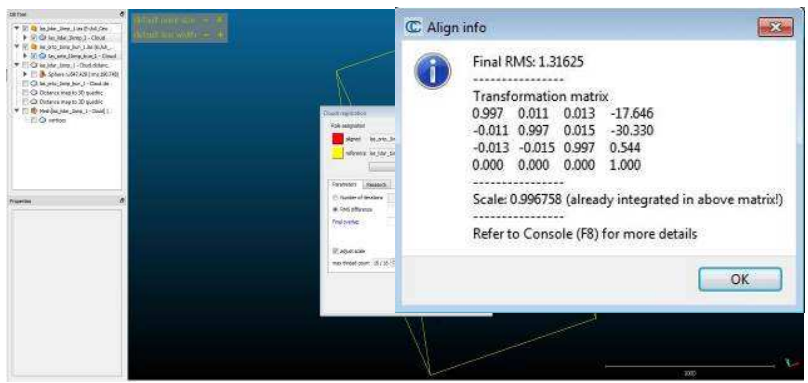

Figure 12. The alignment of the 2 point clouds and the results

A possible method of evaluation of the difference is to compare the geometry of the $2.5 \mathrm{D}$ point cloud with $3 \mathrm{D}$ point cloud with an accuracy two to three times better than the expected matching results. Hausdorff distance (Girardeau-Montaut et al., 2005), mean distance or measuring error in normal are common geometric error measures. The Cloud Compare software allows to compute cloud-to-cloud absolute distances (Tools $>$ Distances), cloud-to-cloud signed distances and cloudto-mesh distances (Tools $>$ Distances). However, the establishment of a good reference dataset is not a straightforward task: pixel-wise matching provides for surface representations at a geometric resolution that is usually higher than the one available from LiDAR data. The results are: the maxim error is $5 \mathrm{~m}$ and Sigma is $3 \mathrm{~m}$ (Figure 13).

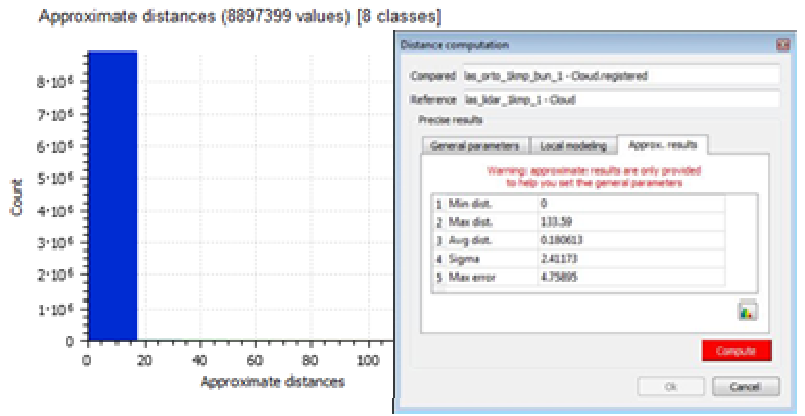

Figure 13. The result of the cloud-to-cloud compare

The next method used was to compute cloud-to-mesh distance. By creating a 3D point cloud mesh from LiDAR data usingminim number of octree is 11 levels. That means that the point cloud is converted to polygon mesh or triangle mesh models automatic with the software. This algorithm of triangle meshes is used to obtain a better quality of the surface area.

The method of minim 11 levels of octree is the simplest method and there were used the default parameters.
Then, the mesh became the reference used in the comparison process. The result parameters are the maximum error $4 \mathrm{~m}$ and Sigma $2 \mathrm{~m}$ shown in Figure 14.

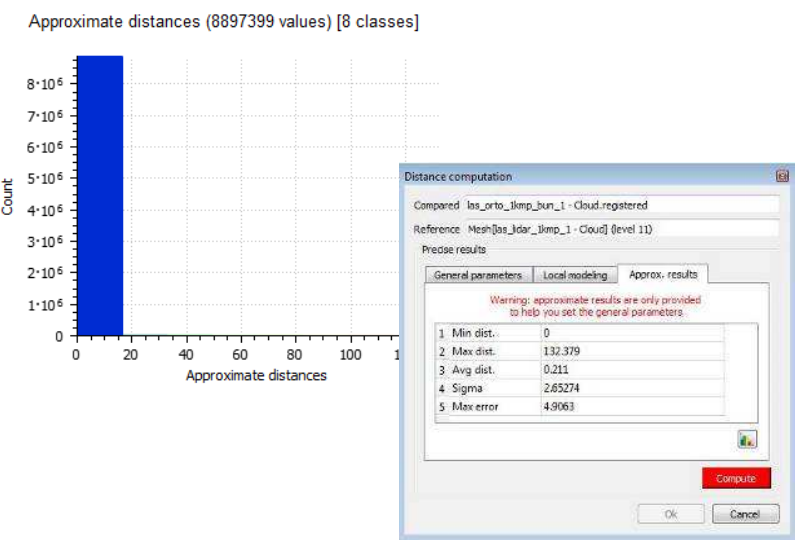

Figure 14. The result of the cloud-to-mesh compare

A quality assurance for elevation products (DSM) should consider three main sources of error: Photogrammetric Modelling Error (PME), due to an imperfect sensor model, Measurement Error (ME), due to errors in the elevation measurement method and Surface Modelling Error (SME), due to interpolation errors. After merging the two point clouds (Figure 15), with the LiDAR as the base of the points, the result was a point cloud with 22 million of $3 \mathrm{D}$ points. The RMS of this point cloud is $4.793 \mathrm{~cm}$.

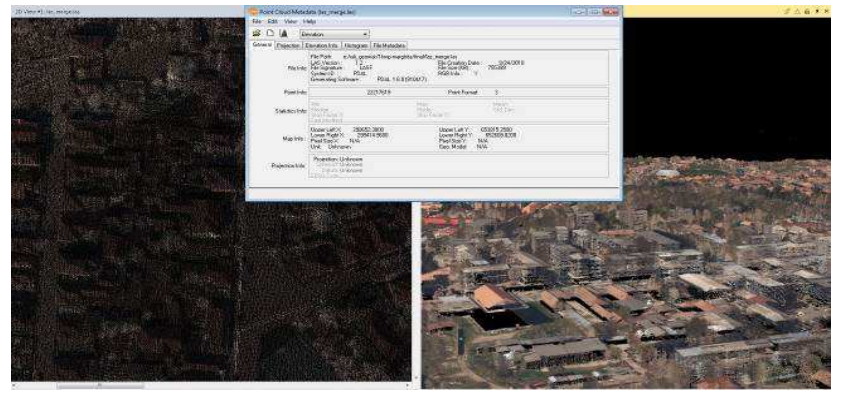

Figure 15. The point cloud resulted

From the point cloud, using all the algorithms mentioned before was generated the raster in a GEOTIFF format with a resolution of $10 \times 10 \mathrm{~cm}$ (Fig 16). The result for the study area is a higher resolution DSM obtained by the improved 3D points from the LiDAR data with the $2.5 \mathrm{D}$ point cloud from aerial imagine. The point cloud has 22 million $3 \mathrm{D}$ points.

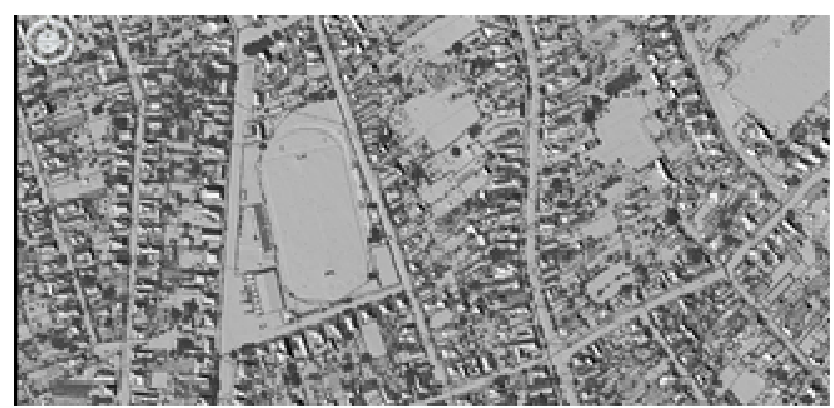

Figure 16. The improve DSM 


\section{CONCLUSIONS}

We can conclude that LiDAR DSM is more accurate than digital aerial camera DSM (shown in Table 2), one of the reasons is the low overlap of the aerial images. The difference between the two methods is due to the parameters used in the project algorithms.

Table 2. The parameters to compare the two DSM

\begin{tabular}{|c|c|c|c|c|}
\hline Nb. & Parameters & $\begin{array}{c}\text { DSM from } \\
\text { Lidar data }\end{array}$ & $\begin{array}{c}\text { DSM from } \\
\text { aerial images }\end{array}$ & $\begin{array}{c}\text { Result from the } \\
\text { compare and the } \\
\text { new DSM }\end{array}$ \\
\hline 1 & Point cloud number & 13 milions & 8 milions & 22 milions \\
\hline 2 & Spatial resolution & $10 \mathrm{~cm} \times 10 \mathrm{~cm}$ & $20 \mathrm{~cm} \times 20 \mathrm{~cm}$ & $10 \mathrm{~cm} \times 10 \mathrm{~cm}$ \\
\hline 3 & RMS $[\mathrm{m}]$ & & 0.07 & 0.04 \\
\hline 4 & Std. dev. $[\mathrm{cm}]$ & 1.71 & 1.95 & - \\
\hline 5 & Mean $[\mathrm{cm}]$ & 4.71 & 4.18 & - \\
\hline 6 & Classes & 2983 & 3650 & - \\
\hline
\end{tabular}

With this improved DSM the geospatial data from the study area will be more accurate. The spatial resolution is $10 \mathrm{~cm}$, data is shown in Figure 16, resulting that the objects of the study area are more detailed and looks like a topographic plan at 1 : 500 scale.

\section{ACKNOWLEDGMENTS}

The author is thankful to the head of the institution Mr RaduDan Nicolae Crisan and to the head of Cartography and Photogrammetry department Ms Margarita Dogaru for constant support and understanding.

\section{REFERENCES}

Axelsson, P., 2000. DEM generation from laser scanner data using adaptive TIN models. The International Archives of the Photogrammetry and Remote Sensing, 33 (B4/1), pp. 110-117.

Bethmann, F., Luhmann T., 2014. Object-based Multi-Image Semi-Global Matching-Concept and first results. ISPRSarchives-XLI -5.

Clark, M. L., Clark, D. B., and Roberts, D. A. 2004. "Smallfootprint lidar estimation of sub-canopy elevation and tree height in a tropical rain forest landscape. Remote Sensing of Environment 91(1), 68-89.

Cramer, M., 2005. Digital Camera Calibration and Validation. EuroSDR: GeoInformatics, 8, 16-19.

Donoghue, D.N.M., Watt, P.J., Cox, N.J., Wilson, J., 2007.

Remote sensing of species mixtures in conifer plantations using LIDAR height and intensity data. Remote Sensing of Environment, 110(4), 509-522.

Fonstad, M., Dietrich, J., Courville, C., Jensen, J., Carbonneau, P., 2011. Topographic structure from motion: a new development in photogrammetric measurement, Earth surface processes and landforms 38, 421-430.

Gamal, L., TAHA, I., A., Sharawi, A., Bekheet, A., 2015. Assessment of the true digital ortho from digital aerial camera, and from LIDAR data, Aviation and Aerial photography division National Authority of Remote Sensing and Space Science (ARSS)-EGYPT.

Girardeau-Montaut, D., Roux, M., Marc, R., Thibault, G., 2005. Change detection on points cloud data acquired with a ground laser scanner. The International Archives of Photogrammetry, Remote Sensing and Spatial Information Sciences, 36(3/W19), pp. 30-35.

Giesen, J., Cazals, F., 2006. Delaunay Triangulation Based Surface Reconstruction, Effective Computational Geometry for Curves and Surfaces (Mathematics and Visualization) (pp.231276).

Haala, N., Rothermel, M., 2012. Dense Multi-Stereo Matching for Hig Quality Digital Elevation. In: Photogrammetrie Fernerkundung - Geoinformation.

Honkavaara, E., Peltoniemi, J., Ahokas, E., Kuittinen, R., Hyyppä, J, Jaakkola, J., Kaartinen, H., Markelin, L., Nurminen, K., Suomalainen, J., 2008. A permanent test field for digital photogrammetric systems. Photogrammetric Engineering \& Remote Sensing, 74(1): 95-106.

Jancso, T., Melykuti, G., 2011. Comparison of digital Terrain Models gained by different technologies, IEEE International Conference on Spatial Data Mining and Geographical Knowledge Services.

Kilian, J., Haala, N., and Englich, M. 1996. Capture and evaluation of airborne laser scanner data. In: The International Archives of Photogrammetry and Remote Sensing, 31(B3), pp.383-388.

Kraus, K. and Pfeifer, N. 2001. Advanced DTM generation from LiDAR data. In: The International Archives of Photogrammetry and Remote Sensing, 34(3/W4), pp. 23-30.

Lane, SN. 2000. The measurement of river channel morphology using digital photogrammetry. Photogrammetric Record 16: 937-961.

Karkalou, E., Stentoumis, C., Karras, G., 2017. Semi-Global Matching with self-adjusting Penalties.ISPRS Volume XLII2/W3,3D Virtual Reconstruction and Visualization of Complex Architectures.

Leberl, F., Thurgood, J., 2004. The promise of Softcopy Photogrammetry Revisited. Graz University of Technology Journal.

Langford, J., Niemann, O., Frazer, G., Wulder, M., Nelson, T., 2006. Exploring small footprint LIDAR intensity data in a forested environment. In: Proceedings, IEEE International Conference on Geoscience and Remote Sensing Symposium, Denver CO, 2416-2419. 
Oniga E., 2017, Fotogrammetria digitală îndrumător de lucrări practice.

Sithole, G., Vosselman, G. 2004. Experimental comparison of Filter algorithms for bare-earth extraction from airborne laser Scanning point clouds. ISPRS Journal of Photogrammetry and Remote Sensing, 59 (1-2), pp. 85-101.

Vosselman, G. 2000. Slope based filtering of laser altimetry Data. In: The International Archives of Photogrammetry and Remote Sensing, 33(B3), pp. 935-942.

Zhang, K., Cheng, S.C., Whitman, D., Shyu, M.L., Yan, J. and Zhang, C., 2003. A progressive morphological filter for removing non-ground measurements from airborne LiDAR data. IEEE Transactions on Geoscience and Remote Sensing, 41(4), pp. 872-882.

Rigel airborne laser scanner Q780, http://www.riegl.com/uploads/tx_pxpriegldownloads/DataSheet _LMS-Q780_2015-03-24.pdf (view at 20 July 2018).

Vexcel Microsoft Ultra Cam LP parameters http://www.gpsicorp.com/UltraCamLp-Specs.pdf (view in 20 July 2018).

Coordinate Systems general knowledges, https://www.geotrafo.com/index.php?page=coosystems\&lang=e $\mathrm{n}$ (view in 28 Sept.2018). 